\title{
Assessing the additional surgical risk of contralateral prophylactic mastectomy and immediate breast implant reconstruction
}

\author{
Kassandra P. Nealon ${ }^{1} \cdot$ Nikhil Sobti $^{1} \cdot$ Michele Gadd $^{2} \cdot$ Michelle Specht $^{2} \cdot$ Eric C. Liao $^{1}$ (D
}

Received: 12 August 2019 / Accepted: 25 September 2019 / Published online: 11 October 2019

○) Springer Science+Business Media, LLC, part of Springer Nature 2019

\begin{abstract}
Introduction There has been a sharp rise in the rate of contralateral prophylactic mastectomy over the last decade, despite the low incidence of new primary cancers predicted for the contralateral breast. This study compares the postoperative complication rates between the diseased breast treated with mastectomy and the contralateral breast that underwent prophylactic mastectomy, followed by immediate bilateral breast implant reconstruction. We hypothesized that there will be no difference in postoperative outcomes between prophylactic and diseased groups, as the surgical approach would be comparable.

Methods After IRB approval, a retrospective chart review identified consecutive unilateral breast cancer patients who underwent bilateral mastectomy and immediate breast reconstruction between May 2008 and May 2018 at a tertiary academic medical center. A paired sample t-test and a penalized logic regression model were constructed to identify relationships between breast laterality and outcomes.

Results A total of 1117 patients with unilateral breast cancer who underwent bilateral mastectomy and immediate breast implant reconstruction were identified. Rates of capsular contracture and infection were significantly greater in the diseased breast, while rates of revision were significantly greater in the contralateral prophylactic breast. There were no statistically significant differences between breasts in rates of explant, skin flap necrosis or hematoma. When adjusted for confounding variables, a higher infection rate was observed in the diseased breast.

Conclusion This study detected significant differences in postoperative complication rates between the diseased and prophylactic breasts following bilateral mastectomy and immediate breast implant reconstruction. Postoperative complications occurred more frequently in the diseased breast compared with low rates of complications in the contralateral prophylactic breast. This information is helpful for preoperative decision making, as surgeons and patients carefully weigh the additional risks of contralateral prophylactic procedure.
\end{abstract}

Keywords Mastectomy $\cdot$ Breast reconstruction $\cdot$ Contralateral prophylactic mastectomy $\cdot$ Plastic surgery $\cdot$ Surgical oncology

Michelle Specht and Eric C. Liao are shared senior authorship.

Eric C. Liao

cliao@partners.org

1 Division of Plastic and Reconstructive Surgery, Department of Surgery, Massachusetts General Hospital, 15 Parkman Street, WACC 435, Boston, MA 02114, USA

2 Division of Surgical Oncology, Department of Surgery, Massachusetts General Hospital, Boston, MA, USA

\section{Introduction}

The rate of prophylactic mastectomy has increased threefold over the last decade. In most breast oncology centers, bilateral mastectomy procedures now outnumber unilateral procedures in the ratio of 2 to 1 [1]. The dramatic increase in prophylactic mastectomy rate is attributed to a convergence of many factors which include increased disease awareness, breast cancer screening efforts, genetic testing, younger patient age at diagnosis, patient anxiety, and potential for improved cosmetic result for bilateral procedures [2-21].

While some studies demonstrate decreased risk of subsequent breast cancer, others suggest that contralateral prophylactic mastectomy (CPM) provides no mortality benefit 
relative to breast-conserving surgery [22-35]. Psychologically, many patients continue to undergo the elective procedure out of anxiety over developing a new primary breast cancer [36-45]. A study conducted by Rosenberg et al. demonstrated that $87 \%$ of women reported high concerns of being diagnosed with contralateral breast cancer in the future, $98 \%$ undergo CPM to decrease their contralateral breast cancer risks, $80 \%$ were confident in their decision, and $90 \%$ would "definitely [choose]" to undergo the procedure again, if given the opportunity [46].

Secondary to the psychologic benefit conferred by CPM, patients often chose to undergo the prophylactic removal of the contralateral breast to maintain breast symmetry following reconstruction [14, 40, 41, 46, 47]. Huang et al. reported that $52.7 \%$ of women stated that the desire for symmetry was a very important factor when deciding to undergo contralateral prophylactic mastectomy [41]. Similarly, Han et al. demonstrated that the desire for breast symmetry was a driving factor when deciding to undergo CPM, in nearly a third of women [14].

Given these patient motivations for prophylactic contralateral procedures, there remains a gap in knowledge for clinicians in how to counsel patients with regard to postoperative complication rates following CPM. The available literature that evaluated clinical outcomes is limited to the investigation of perioperative complications or postoperative outcomes in a non-irradiated patient population [48-50]. Few studies have compared the risk of surgery between the disease versus prophylactic sides, for mastectomy and for implant-based reconstruction [50-52]. These answered questions led this study to assess surgical risks for the prophylactic mastectomy and implant reconstruction: is the surgical risk equivalent between the diseased and prophylactic breasts? This study examined the outcomes of a ten-year retrospective cohort following CPM with regard to the laterality of the breast, comparing the outcome of mastectomy and reconstruction between the disease versus prophylactic breast. Since the surgical procedure is comparable on each side, we hypothesized that the clinical outcome between the disease and contralateral prophylactic breast will be equivalent.

\section{Methods}

\section{Data collection}

A retrospective chart review was conducted at a tertiary medical center with Institutional Review Board approval, observing the declaration of Helsinki. Unilateral breast cancer patients, undergoing a bilateral mastectomy and immediate implant-based breast reconstruction between May 2008 and May 2018 at our institution, were identified. Exclusion criteria included patients who had undergone bilateral autologous reconstruction or delayed contralateral prophylactic mastectomy and reconstruction.

Patient characteristics recorded were age at surgery, body mass index (BMI), obesity, history of smoking, diabetes, type of cancer, cancer grade, laterality of cancer, completion mastectomy, chemotherapy, and pre-mastectomy or post-mastectomy breast radiation. BMI was calculated as mass in kilograms per meter squared. Obesity was defined as BMI $>30$. Smoking was defined as any patient who smoked 6 weeks prior to surgery. Patients who initially underwent breast conserving surgery, but then presented with positive pathological margins and required mastectomy to clear the margin were considered as patients who underwent a completion mastectomy.

Surgical procedure characteristics were documented as follows: mastectomy type (nipple-sparing versus skin-sparing), axillary surgeries (sentinel node biopsy and/or axillary lymph node dissection), reconstruction method (direct-toimplant or tissue expander), location of prostheses placement (subpectoral or prepectoral), implant size, and type of surgical adjunct [Vicryl only, acellular dermal matrix (ADM) only, or Vicryl and ADM]. In this analysis, patients who underwent sentinel lymph node biopsy or axillary lymph node dissection at any time as a part of treatment of the incident cancer were included. For example, if a patient underwent lumpectomy with sentinel lymph node biopsy and then proceeded with a completion mastectomy, we included them in the sentinel lymph node biopsy group. Mastectomies and reconstructions were performed as previously described by our group [53-57]. Evaluation of the post-mastectomy flap thickness, skin color, and capillary refill was coupled with patient risk factors and the surgeon experience to determine final candidacy for the type of mastectomy and reconstruction. In cases where ADM was used, the manufacturers were either Alloderm (LifeCell Corp., Branchburg, NJ) or FlexHD Pliable (Mentor Worldwide, Santa Barbara, CA).

Only postoperative outcomes that required reoperation were recorded, as the treatment for minor complications can vary by the clinical practice of each surgeon. Clinical outcomes which were recorded included mastectomy skin flap necrosis, surgical site infection, hematoma, explantation, capsular contracture, and cosmetic revisions. Mastectomy skin flap necrosis was defined as a non-viable tissue with the evidence of ischemia or eschar formation requiring debridement. Surgical site infection was defined as cutaneous erythema around the incision site, often accompanied by purulent drainage. Explanation was defined as implant removal due to a postoperative complication without subsequent implant placement. Capsular contracture was defined as breast deformity and elevation of the prosthesis resulting from fibrous capsule formation and/or muscle contracture around the prosthesis. For 
the aforementioned complications, laterality of incidence (contralateral prophylactic breast, diseased breast or bilateral) was recorded and compared.

\section{Statistical analysis}

Fisher's exact testing was used to assess categorical variables. A paired sample t-test was implemented to examine the outcome data between breasts. Given the treatment differences between breasts, which may influence complication rates, a penalized (Firth) logistic regression model was constructed to identify the relationship between postoperative complications and covariate variables. Models were controlled for prophylactic v. diseased breast, sentinel node biopsies, axillary lymph node dissection, postmastectomy radiation, location of prostheses placement, type of surgical mesh, type of reconstruction, implant size, and completion mastectomy. Odds ratio, 95\% confidence interval, and $p$ value were calculated for each outcome. Statistical significance was defined as $p<0.05$. Data were analyzed using SPSS 24 (IBM Corp., Armonk, NY).

\section{Results}

\section{Clinical characteristics}

We identified 1117 patients with unilateral breast cancer who underwent bilateral mastectomy and immediate implant-based breast reconstruction (Tables 1,2). The breast cancer pathology types ranged from unilateral DCIS to stage I-III invasive breast carcinoma. The mean patient age was $47.75 \pm 9.08$ years, while the mean BMI was $25.69 \pm 5.62 \mathrm{~kg} / \mathrm{m}^{2}$. Among these patients, nipple-sparing mastectomies were performed in $1170(52.37 \%)$ breasts, whereas skin-sparing mastectomies were performed in $1064(47.63 \%)$ breasts. With regard to reconstruction type, 811 (36.30\%) breasts underwent staged breast reconstruction with tissue expander placement, and 1423 (63.70\%) underwent direct-to-implant breast reconstruction. In total, 105 (9.4\%) patients underwent completion mastectomies, 302 (27.04\%) underwent chemotherapy, 76 (6.8\%) patients had a history of pre-mastectomy breast radiation, and $112(10.03 \%)$ underwent post-mastectomy breast radiation. This study followed the evolution of our surgical department's practice over the last decade, when an increasing number of contralateral prophylactic mastectomies were performed over the course of the study period (Fig. 1). Overall, the mean follow-up time was $63.85 \pm$ 33.39 months.
Table 1 Patient characteristics

\begin{tabular}{|c|c|}
\hline Variable & Total $(\%)$ \\
\hline No. patients & 1117 \\
\hline No. breasts & 2234 \\
\hline Mean age at surgery (year) & $47.75 \pm 9.08$ \\
\hline Mean BMI $\left(\mathrm{kg} / \mathrm{m}^{2}\right)$ & $25.69 \pm 5.62$ \\
\hline Obesity $^{\mathrm{a}}$ & $214(19.16)$ \\
\hline History of smoking & $61(5.46)$ \\
\hline Diabetes & $26(2.33)$ \\
\hline \multicolumn{2}{|l|}{ Laterality of cancer } \\
\hline Right & $560(50.13)$ \\
\hline Left & $557(49.87)$ \\
\hline \multicolumn{2}{|l|}{ Pathology } \\
\hline Invasive ductal carcinoma & $755(67.59)$ \\
\hline Grade 1 & $97(8.68)$ \\
\hline Grade 2 & $347(31.07)$ \\
\hline Grade 3 & $282(25.25)$ \\
\hline Unspecified & $26(2.32)$ \\
\hline Invasive lobular carcinoma & $75(6.71)$ \\
\hline Grade 1 & $8(0.72)$ \\
\hline Grade 2 & $63(5.64)$ \\
\hline Grade 3 & $4(0.36)$ \\
\hline Unspecified & 0 \\
\hline Ductal carcinoma in situ & $820(73.41)$ \\
\hline Grade 1 & $55(4.92)$ \\
\hline Grade 2 & $349(3.12)$ \\
\hline Grade 3 & $394(3.53)$ \\
\hline Unspecified & $22(1.97)$ \\
\hline Lobular carcinoma in situ & $19(1.70)$ \\
\hline Grade 1 & $1(0.08)$ \\
\hline Grade 2 & $10(0.90)$ \\
\hline Grade 3 & $3(2.69)$ \\
\hline Unspecified & $5(0.45)$ \\
\hline Unspecified & $14(1.25)$ \\
\hline Completion mastectomy & $105(9.40)$ \\
\hline Chemotherapy & $302(27.04)$ \\
\hline Radiation & $187(16.74)$ \\
\hline Pre-mastectomy & $76(6.8)$ \\
\hline Post-mastectomy & $112(10.03)$ \\
\hline Follow-up time (months) & $63.85 \pm 33.39$ \\
\hline
\end{tabular}

$B M I$ body mass index, $A D M$ acellular dermal matrix

${ }^{\mathrm{a}} \mathrm{BMI}>30$

\section{Outcomes}

The rate of overall complication in the diseased breast was $10.38 \%$, while the rate of overall complications occurring in the contralateral prophylactic breast was $5.64 \%$, and the rate of overall complications occurring in both breasts was $2.33 \%$. Therefore, the risk of developing a complication in one or both breasts is $13.69 \%$, the risk of developing a 
Table 2 Surgical characteristics

\begin{tabular}{|c|c|c|c|c|}
\hline Variable & Total $(\%)$ & Prophylactic breast & Diseased breast & $p$ \\
\hline Type of mastectomy & & & & $0.000068 *$ \\
\hline Nipple-sparing & $1170(52.37)$ & $632(28.29)$ & $538(24.08)$ & \\
\hline Skin-sparing & $1064(47.63)$ & $485(21.71)$ & $579(25.91)$ & \\
\hline \multicolumn{5}{|l|}{ Axillary management } \\
\hline Pre-mastectomy & $309(13.83)$ & $0(0)$ & $309(27.66)$ & $<0.00001 *$ \\
\hline \multicolumn{5}{|l|}{ Axillary management } \\
\hline Axillary lymph node dissection & $171(7.65)$ & $1(0.09)^{\mathrm{a}}$ & $170(15.22)$ & $<0.00001 *$ \\
\hline Sentinel lymph node biopsy & $1404(62.85)$ & $635(56.85)$ & $769(68.85)$ & $<0.00001 *$ \\
\hline Type of reconstruction & & & & 0.964906 \\
\hline Direct-to-implant & $1423(63.70)$ & $712(31.87)$ & $711(31.83)$ & \\
\hline Tissue expander & $811(36.30)$ & $405(18.13)$ & $406(18.17)$ & \\
\hline Protheses size $(\mathrm{mL})$ & $448.04 \pm 147.54$ & $447.77 \pm 147.38$ & $447.82 \pm 147.27$ & \\
\hline Protheses placement & & & & 1 \\
\hline Subpectoral & $2100(94.0)$ & $1050(47.00)$ & $1050(47.00)$ & \\
\hline Prepectoral & $134(6.0)$ & $67(3.0)$ & $67(3.0)$ & \\
\hline Type of mesh & & & & 1 \\
\hline $\mathrm{ADM}$ & $1488(66.61)$ & $744(33.30)$ & $744(33.30)$ & \\
\hline Vicryl & $668(29.90)$ & 334 (14.95) & 334 (14.95) & \\
\hline Vicryl and ADM & $78(3.49)$ & $39(1.75)$ & $39(1.75)$ & \\
\hline
\end{tabular}

*Statistically significant $(p<0.05)$

${ }^{a}$ Axillary lymph node dissection was performed in the prophylactic breast due to a contralateral axillary metastasis

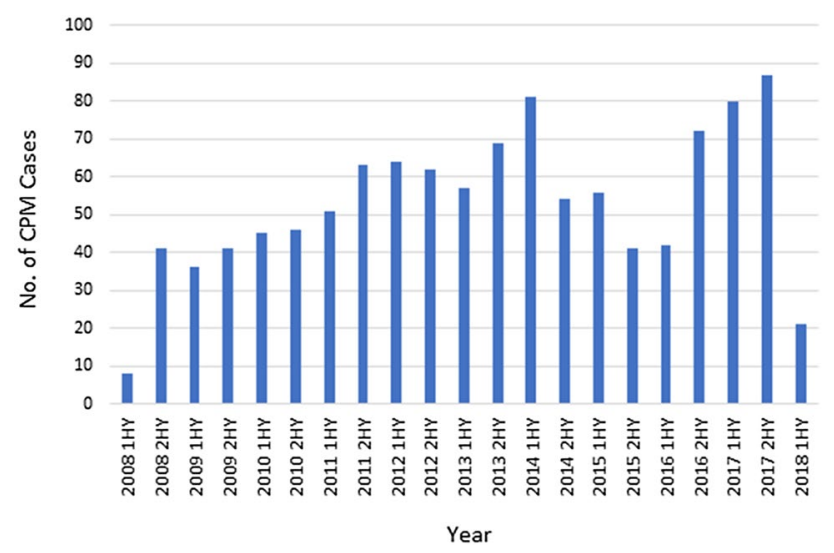

Fig. 1 Trends in contralateral prophylactic mastectomy. Throughout the study period, there is a noticeable increasing trend in the number of contralateral prophylactic mastectomy with reconstruction procedures. Of note, the number of cases depicted in 2008 was from May to December, while the number of cases depicted in 2018 was from January to May

complication in either breast but not both is $11.36 \%$, and the additional risk of having surgery on the contralateral prophylactic breast is $3.31 \%$.

Infection $(6.00 \%)$ was the most common postoperative complication followed by capsular contracture (4.66\%), skin necrosis $(4.57 \%)$, and hematoma (2.78\%). Explanation occurred in $6.89 \%$ of patients and was typically due to infection or mastectomy skin flap necrosis. Explantation which resulted from a postoperative outcome other than capsular contracture, skin necrosis, infection or hematoma, occurred in $0.36 \%$. Capsular contracture $(p=0.021)$ and infection ( $p=0.000095$ ) occurred at significantly higher rates in the diseased breast when compared to the prophylactic breast. Explantation, mastectomy skin necrosis, and hematoma rates did not vary to a statistically significant degree between breasts (Fig. 2). Interestingly, the rate of cosmetic revision was significantly higher in the prophylactic breast (2.78\%) versus the diseased breast (1.43\%) $(p=$ 0.029) (Table 3).

\section{Prophylactic versus diseased breast}

A penalized logistic regression was performed to investigate differences in outcomes between breasts and to account differences in patient habitus and comorbid conditions. The regression model demonstrated a significantly higher rate of infection occurring in the diseased versus contralateral prophylactic breast when controlling for confounding variables such as sentinel node biopsies, axillary lymph node dissections, radiation, location of implant placement, type of surgical mesh, type of reconstruction, implant size, and completion mastectomy (Table 4).

A regression analysis was also performed to exclude patients who had previously undergone lumpectomy 


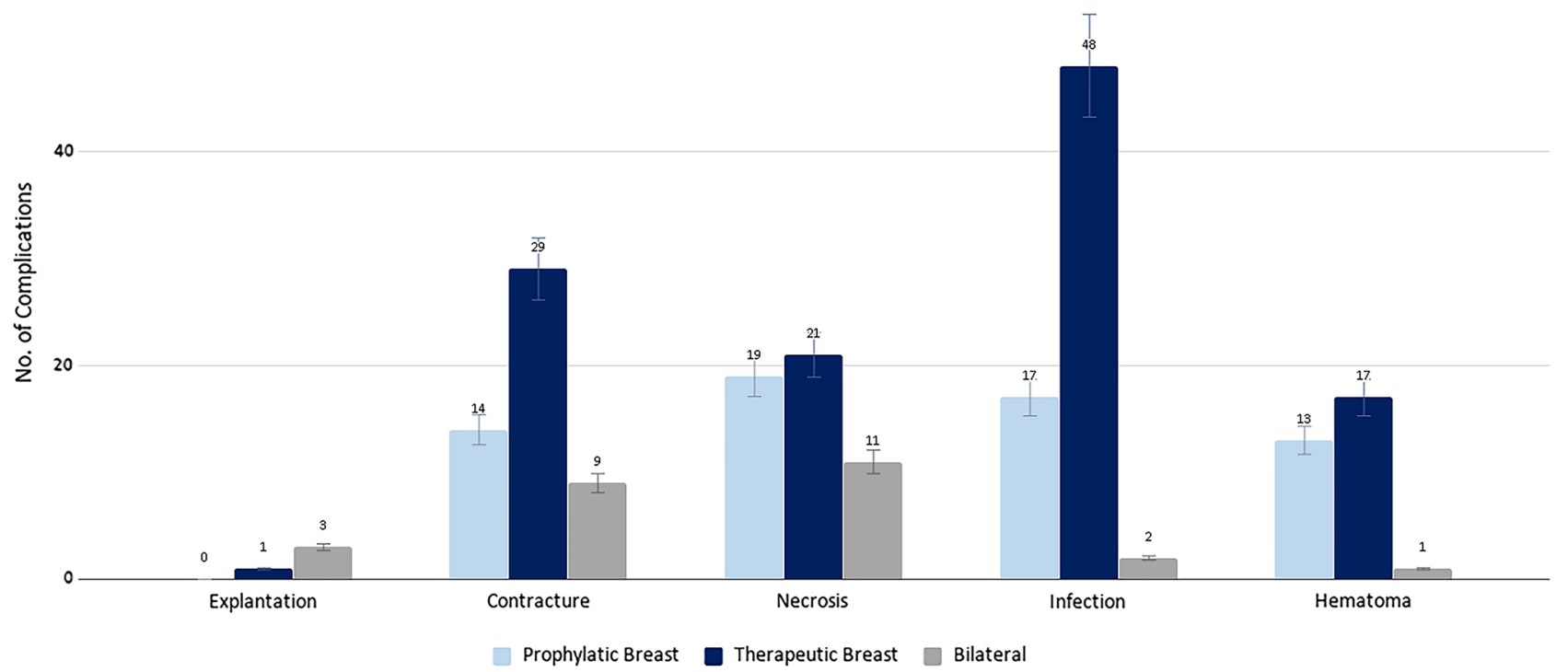

Fig. 2 Comparison of postoperative complications in prophylactic versus diseased breasts. Compared to a contralateral prophylactic breast, rates of capsular contracture and infection were significantly greater in the diseased breast. It is suspected that the routine need for additional treatment on the diseased breast is a contributing factor to the discrepancy in outcomes between breasts

Table 3 Postoperative outcomes

\begin{tabular}{llllll}
\hline Complication & Total $(\%)$ & Prophylactic breast (\%) & Diseased breast (\%) & Bilateral (\%) & $p$ between breasts \\
\hline Overall complication & $205(18.35 \%)$ & $63(5.64 \%)$ & $116(10.38 \%)$ & $26(2.33 \%)$ & $0.000036^{*}$ \\
Explantation** & $4(0.36 \%)$ & 0 & $1(0.09 \%)$ & $3(0.27 \%)$ & - \\
Capsular contracture & $52(4.66 \%)$ & $14(1.25 \%)$ & $29(2.60 \%)$ & $9(0.81 \%)$ & $0.021 *$ \\
$\quad$ Capsular contracture only & $48(4.30 \%)$ & $12(1.07 \%)$ & $27(2.42 \%)$ & $9(0.81 \%)$ & $0.015 *$ \\
Capsular contracture leading to explant & $4(4.66 \%)$ & $2(0.18 \%)$ & $2(0.18 \%)$ & 0 & 1 \\
Skin necrosis & $51(4.57 \%)$ & $19(1.70 \%)$ & $21(1.88 \%)$ & $11(0.98 \%)$ & 0.750 \\
Skin necrosis only & $29(2.60 \%)$ & $13(1.16 \%)$ & $10(0.90 \%)$ & $6(0.54 \%)$ & 0.529 \\
Skin necrosis leading to explant & $22(1.97 \%)$ & $6(0.54 \%)$ & $11(0.98 \%)$ & $5(0.45 \%)$ & 0.223 \\
Infection & $67(6.00 \%)$ & $17(1.52 \%)$ & $48(4.30 \%)$ & $2(0.18 \%)$ & $0.000095 *$ \\
Infection only & $21(1.88 \%)$ & $7(0.63 \%)$ & $14(1.25 \%)$ & 0 & 0.125 \\
Infection leading to explant & $46(4.12 \%)$ & $10(0.90 \%)$ & $34(3.04 \%)$ & $2(0.18 \%)$ & $0.000258 *$ \\
Hematoma & $31(2.78 \%)$ & $13(1.16 \%)$ & $17(1.52 \%)$ & $1(0.09 \%)$ & 0.462 \\
Hematoma only & $30(2.69 \%)$ & $13(1.16 \%)$ & $16(1.43 \%)$ & $1(0.09 \%)$ & 0.575 \\
Hematoma leading to explant & $1(0.09 \%)$ & 0 & $1(0.09 \%)$ & 0 & - \\
Revision & $249(22.29)$ & $31(2.78)$ & $16(1.43)$ & $202(18.08)$ & $0.029 *$ \\
\hline
\end{tabular}

*Statistically significant $(p<0.05)$

**Number of explants that resulted from a complication not listed in the table (i.e. capsular contracture, skin necrosis, infection or hematoma)

with radiation and presented with cancer recurrence which required mastectomy as the next treatment. When adjusted to exclude the lumpectomy recurrence patients who received prior radiation, the regression still revealed a significantly higher rate of infection in the diseased breast when compared to the contralateral prophylactic side. There were no other significant differences in outcomes between breasts (Table 5). 
Table 4 Correlations between patient characteristics and complications

\begin{tabular}{|c|c|c|c|c|c|c|}
\hline \multirow[t]{2}{*}{ Covariate } & $\begin{array}{l}\text { Explantation } \\
\text { Odds ratio } \\
(95 \% \mathrm{CI})\end{array}$ & $\begin{array}{l}\text { Capsular contracture } \\
\text { Odds ratio } \\
(95 \% \mathrm{CI})\end{array}$ & $\begin{array}{l}\text { Skin necrosis } \\
\text { Odds ratio } \\
(95 \% \mathrm{CI})\end{array}$ & $\begin{array}{l}\text { Infection } \\
\text { Odds ratio } \\
(95 \% \mathrm{CI})\end{array}$ & $\begin{array}{l}\text { Hematoma } \\
\text { Odds ratio } \\
(95 \% \mathrm{CI})\end{array}$ & $\begin{array}{l}\text { Revision } \\
\text { Odds ratio } \\
(95 \% \mathrm{CI})\end{array}$ \\
\hline & $p$ & $p$ & $p$ & $p$ & $p$ & $p$ \\
\hline \multirow{4}{*}{ Prophylactic v. diseased } & 0.850 & 1.516 & 1.172 & 2.765 & 1.533 & 0.934 \\
\hline & $0.138-4.473$ & $0.834-2.765$ & $0.672-2.026$ & $1.567-5.008$ & $0.708-3.307$ & $0.739-1.178$ \\
\hline & 0.846 & 0.171 & 0.57 & $0.000 *$ & 0.275 & 0.568 \\
\hline & 3.200 & 0.864 & 1.190 & 0.654 & 0.573 & 1.428 \\
\hline \multirow[t]{3}{*}{ SLNB } & $0.637-31.722$ & $0.512-1.483$ & $0.701-2.081$ & $0.400-1.078$ & $0.282-1.165$ & $1.140-1.793$ \\
\hline & 0.169 & 0.589 & 0.526 & 0.095 & 0.123 & $0.002^{*}$ \\
\hline & 0.897 & 1.587 & 0.634 & 0.685 & 0.415 & 0.909 \\
\hline \multirow[t]{3}{*}{ ALND } & $0.007-8.432$ & $0.705-3.271$ & $0.169-1.721$ & $0.266-1.502$ & $0.045-1.697$ & $0.580-1.385$ \\
\hline & 0.94 & 0.251 & 0.402 & 0.365 & 0.253 & 0.665 \\
\hline & 0.957 & 2.138 & 1.237 & 2.149 & 1.287 & 0.598 \\
\hline \multirow[t]{3}{*}{ XRT } & $0.007-9.728$ & $1.004-4.289$ & $0.470-2.829$ & $1.096-4.019$ & $0.328-3.838$ & $0.363-0.943$ \\
\hline & 0.976 & 0.049 & 0.643 & $0.027^{*}$ & 0.686 & $0.026^{*}$ \\
\hline & 1.040 & 0.306 & 1.818 & 0.682 & 0.510 & 0.438 \\
\hline \multirow[t]{3}{*}{ Subpectoral v. prepectoral } & $0.008-10.465$ & $0.034-1.171$ & $0.700-4.035$ & $0.182-1.837$ & $0.056-2.036$ & $0.234-0.757$ \\
\hline & 0.979 & 0.091 & 0.202 & 0.483 & 0.388 & $0.002 *$ \\
\hline & 0.523 & 0.780 & 0.871 & 0.956 & 0.836 & 0.857 \\
\hline \multirow[t]{3}{*}{ Vicryl v. ADM } & $0.120-2.442$ & $0.459-1.362$ & $0.514-1.516$ & $0.571-1.652$ & $0.403-1.844$ & $0.685-1.078$ \\
\hline & 0.389 & 0.375 & 0.617 & 0.868 & 0.644 & 0.187 \\
\hline & 2.002 & 1.133 & 1.171 & 1.387 & 0.729 & 1.305 \\
\hline \multirow[t]{3}{*}{ TE v. DTI } & $0.445-9.660$ & $0.60-1.912$ & $0.681-1.982$ & $0.838-2.275$ & $0.320-1.536$ & $1.050-1.619$ \\
\hline & 0.36 & 0.644 & 0.561 & 0.201 & 0.415 & $0.016^{*}$ \\
\hline & 1.006 & 1.001 & 1.001 & 1.002 & 1.004 & 1.001 \\
\hline \multirow[t]{3}{*}{ Implant size } & $1.001-1.012$ & $1.00-1.003$ & $0.999-1.002$ & $1.001-1.004$ & $1.002-1.006$ & $1.001-1.002$ \\
\hline & $0.013^{*}$ & 0.097 & 0.548 & $0.008^{*}$ & $0.001^{*}$ & $0.001^{*}$ \\
\hline & 10.135 & 0.674 & 0.456 & 0.437 & 1.174 & 1.280 \\
\hline \multirow[t]{2}{*}{ Completion mastectomy } & $1.480-68.786$ & $0.135-2.085$ & $0.051-1.765$ & $0.088-1.334$ & $0.225-3.999$ & $0.779-2.044$ \\
\hline & $0.021^{*}$ & 0.533 & 0.296 & 0.162 & 0.823 & 0.322 \\
\hline
\end{tabular}

*Statistically significant $(p<0.05)$

\section{Discussion}

Breast cancer will affect nearly $13 \%$ of US women during their lifetime [49]. Typically, the risk of breast cancer in the contralateral breast is due to a new primary tumor, not the regional spread of disease from one breast to another. After 10 years of primary breast cancer diagnosis, the average rate of contralateral breast cancer occurrence for the general population is estimated to be 5-10\% [58-65]. In contrast, patients harboring a BRCA1/2 pathogenic genetic variant, the risk of breast cancer occurrence is about $10-30 \%$ [66-73].

In the past decade, many more women have chosen to undergo a CPM for a variety of reasons $[14,17,19,34$, $40-43,46,47,74,75]$. Since the contralateral prophylactic procedure is elective, it is important to critically weigh the additional risk of this procedure. This study presents one of the largest comparisons of postoperative outcomes in diseased versus contralateral prophylactic breasts, following bilateral mastectomy and immediate breast implant reconstruction. The evaluation of postoperative outcomes in reconstructed breasts in the same patient mitigates confounding patient characteristics, whereas the penalized regression model controls for potential differences in treatment and morbidity between breasts.

Analysis here revealed that the added risk of having surgery on the contralateral prophylactic breast is $3.31 \%$. Capsular contracture and infection had a significantly higher chance of occurring in the diseased versus prophylactic breast ( $p=0.021$ and $p=0.000095$, respectively). It is likely that these higher rates of complications stem from the treatment of the diseased breast. Often diseased breasts 
Table 5 Correlations between patient characteristics and complications when excluding pre-mastectomy radiation patients

\begin{tabular}{|c|c|c|c|c|c|c|}
\hline \multirow[t]{2}{*}{ Covariate } & $\begin{array}{l}\text { Explantation } \\
\text { Odds ratio } \\
(95 \% \mathrm{CI})\end{array}$ & $\begin{array}{l}\text { Capsular contracture } \\
\text { Odds ratio } \\
(95 \% \mathrm{CI})\end{array}$ & $\begin{array}{l}\text { Skin necrosis } \\
\text { Odds ratio } \\
(95 \% \mathrm{CI})\end{array}$ & $\begin{array}{l}\text { Infection } \\
\text { Odds ratio } \\
(95 \% \mathrm{CI})\end{array}$ & $\begin{array}{l}\text { Hematoma } \\
\text { Odds ratio } \\
(95 \% \mathrm{CI})\end{array}$ & $\begin{array}{l}\text { Revision } \\
\text { Odds ratio } \\
(95 \% \mathrm{CI})\end{array}$ \\
\hline & $p$ & $p$ & $p$ & $p$ & $p$ & $p$ \\
\hline \multirow{4}{*}{ Prophylactic vs. diseased } & 0.850 & 1.520 & 1.155 & 2.790 & 1.502 & 0.931 \\
\hline & $0.139-4.468$ & $0.838-2.773$ & $0.658-2.002$ & $1.576-5.068$ & $0.692-3.245$ & $0.736-1.176$ \\
\hline & 0.846 & 0.168 & 0.612 & $0.000^{*}$ & 0.299 & 0.553 \\
\hline & 3.209 & 0.996 & 1.189 & 0.623 & 0.624 & 1.429 \\
\hline \multirow[t]{3}{*}{ SLNB } & $0.641-31.753$ & $0.578-1.758$ & $0.690-2.115$ & $0.371-1.053$ & $0.304-1.288$ & $1.138-1.802$ \\
\hline & 0.167 & 0.988 & 0.539 & 0.077 & 0.199 & $0.002^{*}$ \\
\hline & 0.875 & 1.395 & 0.777 & 0.861 & 0.465 & 0.900 \\
\hline \multirow[t]{3}{*}{ ALND } & $0.007-8.256$ & $0.564-3.059$ & $0.206-2.136$ & $0.331-1.914$ & $0.051-1.914$ & $0.560-1.402$ \\
\hline & 0.927 & 0.447 & 0.654 & 0.729 & 0.328 & 0.650 \\
\hline & 1.484 & 2.425 & 0.754 & 1.704 & 1.351 & 0.323 \\
\hline \multirow[t]{3}{*}{ PMRT } & $0.011-15.753$ & $0.965-5.441$ & $0.150-2.389$ & $0.688-3.736$ & $0.260-4.604$ & $0.138-0.650$ \\
\hline & 0.804 & 0.059 & 0.666 & 0.233 & 0.679 & $0.001 *$ \\
\hline & 1.012 & 0.330 & 2.034 & 0.308 & 0.555 & 0.464 \\
\hline \multirow[t]{3}{*}{ Subpectoral vs. prepectoral } & $0.008-10.288$ & $0.037-1.271$ & $0.780-4.549$ & $0.034-1.183$ & $0.061-2.219$ & $0.247-0.806$ \\
\hline & 0.994 & 0.12 & 0.136 & 0.095 & 0.456 & $0.005^{*}$ \\
\hline & 0.525 & 0.834 & 0.943 & 1.044 & 0.945 & 0.848 \\
\hline \multirow[t]{3}{*}{ Vicryl vs. ADM } & $0.121-2.452$ & $0.480-1.492$ & $0.546-1.680$ & $0.605-1.874$ & $0.446-2.158$ & $0.674-1.070$ \\
\hline & 0.393 & 0.53 & 0.836 & 0.879 & 0.887 & 0.164 \\
\hline & 2.010 & 1.177 & 1.141 & 1.256 & 0.774 & 1.285 \\
\hline \multirow[t]{3}{*}{ TE vs. DTI } & $0.447-9.660$ & $0.675-2.020$ & $0.649-1.968$ & $0.736-2.111$ & $0.339-1.644$ & $1.029-1.602$ \\
\hline & 0.357 & 0.56 & 0.642 & 0.397 & 0.515 & $0.027 *$ \\
\hline & 1.006 & 1.001 & 1.001 & 1.002 & 1.004 & 1.001 \\
\hline \multirow[t]{3}{*}{ Implant size } & $1.001-1.011$ & $1.000-1.003$ & $0.999-1.002$ & $1.000-1.004$ & $1.002-1.006$ & $1.001-1.002$ \\
\hline & $0.013^{*}$ & 0.11 & 0.488 & $0.014^{*}$ & $0.001^{*}$ & $0.000^{*}$ \\
\hline & 10.135 & 0.685 & 0.478 & 0.263 & 1.194 & 0.809 \\
\hline \multirow[t]{2}{*}{ Completion mastectomy } & $1.486-68.375$ & $0.138-2.123$ & $0.053-1.863$ & $0.029-1.011$ & $0.229-4.063$ & $0.809-2.138$ \\
\hline & $0.021^{*}$ & 0.552 & 0.332 & 0.052 & 0.806 & 0.251 \\
\hline
\end{tabular}

*Statistically significant $(p<0.05)$

undergo sentinel node biopsy and axillary lymph node dissection at the time of mastectomy. This added intervention involves the manipulation of additional tissue planes and longer procedure times, both of which have been shown to increase infection rates [76-79]. As expected, there was a significant difference in sentinel node biopsies and axillary lymph node dissections between the prophylactic and diseased breasts $(p=<0.00001, p=<0.00001)$. While neither sentinel node biopsies nor axillary lymph node dissections showed a significant correlation to capsular contracture or infection in the penalized logistic regression, a study conducted by Lucci et al. reported a significant difference in wound infections between patients who underwent sentinel node biopsies only and those who underwent sentinel node biopsies and axillary lymph node dissections ( $p$ $=0.0026)$. [48]. We speculate that the additive effects of additional treatment correlate to higher complication rates in the diseased breast. Moreover, any diseased breast which underwent previous lumpectomy was exposed to pre-mastectomy radiation, and any diseased breast with node positive disease after mastectomy was exposed to post-mastectomy radiation. Exposure to irradiation leads to skin damage, soft tissue breakdown, local edema, and skeletal muscle fibrosis, which may further increase the risk of complications [80-84]. Spear et al. explained that even though the risks of prosthetic reconstruction complications are dependent on the timing and aggressiveness of the radiation, breast irradiation generally results in higher rates of infection and capsular contracture, which our results also illustrate [81].

Revision rates were higher in the prophylactic breast $(2.78 \%)$ compared to the diseased breast $(1.43 \%)(p=$ 0.029). However, it is important to note that a greater 
significant difference was seen when comparing revisions rates in the prophylactic breast alone $(2.78 \%)$ to bilateral revision rates $(18.08 \%)(p<0.0001)$. Most often, revisions consisted of mastopexy procedures to improve the symmetry between breasts and scar revisions to lessen the thickening of the scar or fat grafting to mitigate implant wrinkling or to improve contour irregularities. The difference in revision rates between the prophylactic breast and the diseased breast was no longer significant when adjusting for all confounding variables in the penalized regression model. Nevertheless, the revision rates of this study compare favorably with previously published revision rates for immediate implant-based reconstruction [57, 85].

In addition to overall postoperative outcomes, we were also interested in determining whether certain outcomes were influenced by specific treatments or risk factors. Interestingly, in the penalized regression model, infection was the only complication that remained significantly higher in the diseased versus contralateral prophylactic breast (Infection OR 2.12, CI 0.225-1.387, $p$ 0.006). Furthermore, this remained true when excluding patients who received pre-mastectomy radiation (Infection OR 2.104, CI $0.17-1.341, p 0.011$ ). A similar study conducted by Crosby et al. failed to detect a significant difference in infection rates, between diseased and contralateral prophylactic breasts, following both implant and autologous breast reconstructions [49]. However, it is likely that their exclusion of irradiated patients contributed to discrepancies between our reported outcomes.

The main limitation of this study is its retrospective design. It is also possible that the study suffered from regional or institutional selection bias, as the evaluation was performed at a single tertiary academic center. Differences in operating techniques and postoperative clinical management among the plastic surgeons within the department could have also introduced variance in postoperative outcomes. Despite these limitations, this study demonstrates additive risks conferred with CPMs and immediate implantbased reconstruction within a large cohort of patients and long-term follow-up.

It has been suggested that decision making for CPM is highly influenced by surgeons, given their significant role in patient education $[40,75,86]$. The National Comprehensive Cancer Network Practice Guidelines stresses the importance of physicians creating a "shared decision-making environment" with their patients [87]. Patient factors that have been shown to contribute to the decision to undergo CPM include young age, white ethnicity, marital status, positive family history of breast cancer, positive genetic testing, and access to immediate breast reconstruction $[13,14,17,47,50$, 88-94]. Therefore, thorough preoperative management and consultation is critical. Our analysis will allow patients and treating surgeons to balance these factors against the risk of postoperative complications from undergoing a contralateral prophylactic mastectomy.

\section{Conclusion}

The risk of developing a postoperative capsular contracture and infection, following mastectomy and immediate breast reconstruction, is significantly higher in a diseased breast compared to a contralateral prophylactic breast. This study demonstrates a $3.22 \%$ additional risk of any complication occurring in a prophylactic breast. Patients and surgeons should carefully consider this additional risk when electing to undergo contralateral prophylactic mastectomy, especially if the patient has additional comorbid conditions such as prior radiation treatment, smoking status or obesity. Future multi-institutional prospective studies are recommended to gain higher level clinical evidence to better assess the additional risks of contralateral prophylactic mastectomy.

Acknowledgements We would like to acknowledge our patient Dr. Brigitte Robertson for asking the question and encouraging us to develop this study.

Funding No funds were received for this study.

\section{Compliance with ethical standards}

Conflicts of interest Eric Liao M.D. Ph.D has consultant agreements but is explicitly not a speaker for Musculoskeletal Transplant Foundation and Allergan Inc., manufacturers of FlexHD and AlloDerm, respectively. No funds were received for this clinical study.

Ethical approval All procedures performed in studies involving human participants were in accordance with the ethical standards of the institutional and/or national research committee and with the 1964 Helsinki declaration and its later amendments or comparable ethical standards.

Informed consent Informed consent was obtained from all individual participants included in the study.

\section{References}

1. Surgeons ASoP (2017) Plastic surgery statistics reports. American Society of Plastic Surgeons

2. Marmor RA, Dai W, Jiang X, Wang S, Blair SL, Huh J (2017) Increase in contralateral prophylactic mastectomy conversation online unrelated to decision-making. J Surg Res 218:253-260

3. Venetis M, MacGeorge E, Baptiste D, Mouton A, Friley L, Pastor R, Hatten K, Lagoo J, Bowling M, Clare S (2018) Social network, surgeon, and media influence on the decision to undergo contralateral prophylactic mastectomy. Am J Clin Oncol 41:519-525

4. Monticciolo DL, Newell M, Hendrick RE, Helvie MA, Moy L, Monsees B, Kopans DB, Eby PR, Sickles E (2017) Breast cancer screening for average-risk women: recommendations from 
the ACR commission on breast imaging. J Am Coll Radiol 14:1137-1143

5. Mokdad AH, Dwyer-Lindgren L, Fitzmaurice C, Stubbs RW, Bertozzi-Villa A, Morozoff C, Charara R, Allen C, Naghavi M, Murray CJ (2017) Trends and patterns of disparities in cancer mortality among US counties, 1980-2014. JAMA 317:3880406

6. McLaughlin CC, Lillquist PP, Edge SB (2009) Surveillance of prophylactic mastectomy: trends in use from 1995 through 2005. Cancer 115:5404-5412

7. Wood W (2008) Increasing use of contralateral prophylactic mastectomy: a counterintuitive trend. Oncology 22:545-551

8. Frost MH, Slezak J, Tran NV, Williams CI, Johnson JL, Woods JE, Petty PM, Donohue JH, Grant CS, Sloan JA, Sellers TA, Hartmann LC (2005) Satisfaction after contralateral prophylactic mastectomy: the significance of mastectomy type, reconstructive complications, and body appearance. J Clin Oncol 23:7849-7856

9. Tuttle TM, Habermann E, Grund EH, Morris TJ, Virnig BA (2007) Increasing use of contralateral prophylactic mastectomy for breast cancer patients: a trend toward more aggressive surgical treatment. J Clin Oncol 25:5203-5209

10. Tuttle TM, Jarosek S, Habermann EB, Arrington A, Abraham A, Morris TJ (2009) Increasing rates of contralateral prophylactic mastectomy among patients with ductal carcinoma in situ. J Clin Oncol 27:1362-1367

11. Yao K, Stewart A, Winchester DJ, Winchester DP (2010) Trends in contralateral prophylactic mastectomy for unilateral cancer: a report from the National Cancer Data Base, 1998-2007. Ann Surg Oncol 10:2554-2562

12. Pesce CE, Liederbach E, Czechura T, Winchester DJ, Yao K (2003) Changing surgical trends in young patients with early stage breast cancer, 2003 to 2010: a report from the National Cancer Data Base. J Am Coll Surg 1:19-28

13. Stucky CC, Gray R, Wasif N, Dueck AC, Pockaj BA (2010) Increase in contralateral prophylactic mastectomy: echoes of a bygone era? Surgical trends for unilateral breast cancer. Ann Surg Oncol 17:330-337

14. Han E, Johnson N, Glissmeyer M, Wagie T, Carey B, DelaMelena T, Nelson J (2011) Increasing incidence of bilateral mastectomies: the patient perspective. Am J Surg 201:615-618

15. Dragun AE, Pan J, Riley EC, Kruse B, Wilson MR, Rai S, Jain D (2013) Increasing use of elective mastectomy and contralateral prophylactic surgery among breast conservation candidates: a 14-year report from a comprehensive cancer center. Am J Clin Oncol 36:275-380

16. McGuire KP, Santillan A, Kaur P, Meade T, Parbhoo J, Mathias M, Shamehdi C, Davis M, Ramos D, Cox CE (2009) Are mastectomies on the rise? A 13-year trend analysis of the selection of mastectomy versus breast conservation therapy in 5865 patients. Ann Surg Oncol 16:2682-2690

17. Arrington AK, Jarosek S, Virnig BA, Habermann EB, Tuttle TM (2009) Patient and surgeon characteristics associated with increased use of contralateral prophylactic mastectomy in patients with breast cancer. Ann Surg Oncol 16:2697-2704

18. Jones NB, Wilson J, Kotur L, Stephens J, Farrar WB, Agnese DM (2009) Contralateral prophylactic mastectomy for unilateral breast cancer: an increasing trend at a single institution. Ann Surg Oncol $16: 2691-2696$

19. Hooper R, Hsu J, Duncan A, Bensenhaver J, Newman L, Kidwell K, Chung K, Momoh A (2019) Breast cancer knowledge and decisions made for contralateral prophylactic mastectomy: a survey of surgeons and women in the general population. Plast Reconstr Surg 143:936-945

20. Cemal Y, Albornoz CR, Disa JJ et al (2013) A paradigm shift in U.S. breast reconstruction: Part 2. The influence of changing mastectomy patterns on reconstructive rate and method. Plast Reconstr Surg 131:320e-326e
21. Albornoz CR, Matros E, Lee CN et al (2015) Bilateral mastectomy versus breast-conserving surgery for early-stage breast cancer: the role of breast reconstruction. Plast Reconstr Surg 135:1518-1526

22. Mutter RW, Frost M, Hoskin TL, Johnson JL, Hartmann LC, Boughey JC (2015) Breast cancer after prophylactic mastectomy (bilateral or contralateral prophylactic mastectomy), a clinical entity: presentation, management, and outcomes. Breast Cancer Res Treat 153:183-190

23. Rebbeck TRFT, Friebel T, Lynch HT, Neuhausen SL, van't Veer L, Garber JE, Evans GR, Narod SA, Isaacs C, Matloff E, Daly MB, Olopade OI, Weber BL (2004) Bilateral prophylactic mastectomy reduces breast cancer risk in BRCA1 and BRCA2 mutation carriers: the PROSE Study Group. J Clin Oncol 22:1055-1062

24. Hartmann LCSD, Schaid D, Woods JE, Crotty TP, Myers JL, Arnold PG, Petty PM, Sellers TA, Johnson JL, McDonnell SK, Frost MH, Jenkins RB (1999) Efficacy of bilateral prophylactic mastectomy in women with a family history of breast cancer. $\mathrm{N}$ Engl J Med 340:77-84

25. McDonnell SK, Schaid D, Myers JL, Grant CS, Donohue JH, Woods JE, Frost MH, Johnson JL, Sitta DL, Slezak JM, Crotty TB, Jenkins RB, Sellers TA, Hartmann LC (2001) Efficacy of contralateral prophylactic mastectomy in women with a personal and family history of breast cancer. J Clin Oncol 19:3938-3943

26. van Sprundel TC, Schmidt MK, Rookus MA, Brohet R, van Asperen CJ, Rutgers EJTH, van't Veer LJ, Tollenaar RAEM (2005) Risk reduction of contralateral breast cancer and survival after contralateral prophylactic mastectomy in BRCA1 or BRCA2 mutation carriers. Br J Cancer 93:287-292

27. Meijers-Heijboer H, van Geel B, van Putten WL, Henzen-Logmans SC, Seynaeve C, Menke-Pluymers MB, Bartels CC, Verhoog LC, van den Ouweland AM, Niermeijer MF, Brekelmans CT, Klijn JG (2001) Breast cancer after prophylactic bilateral mastectomy in women with a BRCA1 or BRCA2 mutation. N Engl J Med 345:159-164

28. Kurian AW, Lichtensztajn D, Keegan TH, Nelson DO, Clarke CA, Gomez SL (2014) Use of and mortality after bilateral mastectomy compared with other surgical treatments for breast cancer in California, 1998-2011. JAMA 312:902-914

29. Bedrosian I, Yu C, Chang GJ (2010) Population-based study of contralateral prophylactic mastectomy and survival outcomes of breast cancer patients. J Natl Cancer Inst 102:401-409

30. Portschy PR, Kuntz K, Tuttle TM (2014) Survival outcomes after contralateral prophylactic mastectomy: a decision analysis. J Natl Cancer Inst. https://doi.org/10.1093/jnci/dju160

31. Yao K, Winchester D, Czechura T, Huo D (2013) Contralateral prophylactic mastectomy and survival: report from the National Cancer Data Base, 1998-2002. Breast Cancer Res Treat 142:465-467

32. Yu TJ, Liu Y, Hu X, Di GH (2018) No survival improvement of contralateral prophylactic mastectomy among women with invasive lobular carcinoma. J Surg Oncol 118:928-935

33. Herrinton LJ, Barlow WE, Yu O et al (2005) Efficacy of prophylactic mastectomy in women with unilateral breast cancer: a cancer research network project. J Clin Oncol 23:4275-4286

34. Katz SJ, Morrow M (2013) Contralateral prophylactic mastectomy for breast cancer: addressing peace of mind. JAMA 310:793-794

35. Wong SM, Freedman R, Sagara Y, Aydogan F, Barry WT, Golshan M (2017) Growing use of contralateral prophylactic mastectomy despite no improvement in long-term survival for invasive breast cancer. Ann Surg 265:581-589

36. Momoh AO, Cohen W, Kidwell KM, Hamill JB, Qi J, Pusic AL, Wilkins EG, Matros E (2017) Tradeoffs associated with contralateral prophylactic mastectomy in women choosing breast reconstruction: results of a prospective multicenter cohort. Ann Surg 266:158-164 
37. Geiger AM, West C, Nekhlyudov L, Herrinton LJ, Liu IL, Altschuler A, Rolnick SJ, Harris EL, Greene SM, Elmore JG, Emmons KM, Fletcher SW (2006) Contentment with quality of life among breast cancer survivors with and without contralateral prophylactic mastectomy. J Clin Oncol 24:1350-1356

38. Brandberg Y, Sandelin K, Erikson S, Jurell G, Liljegren A, Lindblom A, Linden A, von Wachenfeldt A, Wickman M, Arver B (2008) Psychological reactions, quality of life, and body image after bilateral prophylactic mastectomy in women at high risk for breast cancer: a prospective 1-year follow-up study. J Clin Oncol 26:3943-3949

39. Boughey J, Attai D, Chen S, Cody H, Dietz J, Feldman S, Greenberg C, Kass R, Landercasper J, Lemaine V, MacNeill F, Song D, Staley A, Wilke L, Willey S, Yao K, Margenthaler J (2016) Contralateral prophylactic mastectomy (CPM) consensus statement from the american society of breast surgeons: data on CPM outcomes and risks. Ann Surg Oncol 23:3100-3105

40. Buchanan PJ, Abdulghani M, Waljee JF, Kozlow JH, Sabel MS, Newman LA, Chung KC, Momoh AO (2016) An analysis of the decisions made for contralateral prophylactic mastectomy and breast reconstruction. Plast Reconstr Surg 138:29-40

41. Huang J, Chagpar A (2018) Factors associated with decision to undergo contralateral prophylactic mastectomy versus unilateral mastectomy. Am J Surg 218:170-174

42. Parker P, Peterson S, Shen Y, Bedrosian I, Black D, Thompson A (2018) Prospective study of psychosocial outcomes of having contralateral prophylactic mastectomy among women with nonhereditary breast cancer. J Clin Oncol 36:2630-2638

43. Manne S, Smith B, Mitarotondo A, Frederick S, Toppmeyer D, Kirstein L (2018) Decisional conflict among breast cancer patients considering contralateral prophylactic mastectomy. Patient Educ Couns 102:902-908

44. Hawley ST, Jagsi R, Morrow M et al (2014) Social and clinical determinants of contralateral prophylactic mastectomy. JAMA Surg 149:582-589

45. Soran A, Ibrahim A, Kanbour M et al (2015) Decision making and factors influencing long-term satisfaction with prophylactic mastectomy in women with breast cancer. Am J Clin Oncol 38:179-183

46. Rosenberg STM, Meyer M, Sepucha K, Gelber S, HirshfieldBartek J, Troyan S, Morrow M, Schapira L, Come S, Winer E, Partridge A (2014) Perceptions, knowledge, and satisfaction with contralateral prophylactic mastectomy among young women with breast cancer: a cross-sectional survey. Ann Intern Med 159:373-381

47. Hoskin TLHT, Degnim AC, Jakub JW, Jacobson SR, Boughey JC (2016) Use of immediate breast reconstruction and choice for contralateral prophylactic mastectomy. Surgery 159:1199-1209

48. Silva AKLB, Yao KA, Song DH, Sisco M (2015) The effect of contralateral prophylactic mastectomy on perioperative complications in women undergoing immediate breast reconstruction: a NSQIP analysis. Ann Surg Oncol 22:3474-3480

49. Crosby MAGP, Selber JC, Adelman DM, Sacks JM, Villa MT, Lin HY, Park SJ, Baumann DP (2011) Reconstructive outcomes in patients undergoing contralateral prophylactic mastectomy. Plast Reconstr Surg 128:1025-1033

50. Huang JCA (2018) Complications in patients with unilateral breast cancer who undergo contralateral prophylactic mastectomy versus unilateral mastectomy. Surgery 164:1347-1350

51. Alba B, Schultz BD, Cohen D, Qin AL, Chan W, Tanna N (2019) Risk-to-benefit relationship of contralateral prophylactic mastectomy: the argument for bilateral mastectomies with immediate reconstruction. Plast Reconstr Surg 144:1-9

52. Osman F, Saleh F, Jackson TD, Corrigan MA, Cil T (2013) Increased postoperative complications in bilateral mastectomy patients compared to unilateral mastectomy: an analysis of the NSQIP database. Ann Surg Oncol 20:3212-3217

53. Kobraei ECR, Gadd M, Austen W, Liao EC (2016) Avoiding breast animation deformity with pectoralis-sparing subcutaneous direct-to-implant breast reconstruction. Plast Reconstr Surg Glob Open 4:708

54. Colwell ASCJ (2017) Nipple-sparing mastectomy and direct-toimplant breast reconstruction. Plast Reconstr Surg 140:44S-50S

55. As C (2012) Direct-to-implant breast reconstruction. Gland Surg $1: 139-141$

56. LE Gfrerer L (2018) Technique refinement in prepectoral implant based reconstruction with vicryl mesh pocket and acellular dermal matrix support. Plast Reconstr Surg Glob Open 6:1749

57. Clarke-Pearson EM, Lin A, Hertl C, Austen WG, Colwell AS (2016) Revisions in implant-based breast reconstruction: how does direct-to-implant measure up? Plast Reconstr Surg. https:// doi.org/10.1097/PRS.0000000000002173

58. Cancer Stat Facts: Female Breast Cancer US Department of Health and Human Services, National Institute of Health, National Cancer Institute

59. Gao X, Fisher SG, Emami B (2003) Risk of second primary cancer in the contralateral breast in women treated for early-stage breast cancer: a population-based study. Int J Radiat Oncol Biol Phys 56:1038-1045

60. Lee JM, Buist DS, Houssami N et al (2015) Five-year risk of interval-invasive second breast cancer. J Natl Cancer Inst. https:// doi.org/10.1093/jnci/djv109

61. Ricceri F, Fasanelli F, Giraudo MT et al (2015) Risk of second primary malignancies in women with breast cancer: results from the European prospective investigation into cancer and nutrition (EPIC). Int J Cancer 137:940-948

62. Abbott ARN, Pappas-Varco S, Kuntz K, Kerr E, Tuttle T (2011) Perceptions of contralateral breast cancer: an overestimation of risk. Ann Surg Oncol 18:3129-3136

63. Hislop TG, Elwood JM, Coldman AJ, Spinelli JJ, Worth AJ, Ellison LG (1984) Second primary cancers of the breast: incidence and risk factors. Br J Cancer 49:79-85

64. Yeatman TJ, Lyman GH, Smith SK, Reintgen DS, Cantor AB, Cox CE (1997) Bilaterality and recurrence rates for lobular breast cancer: considerations for treatment. Ann Surg Oncol 4:198-202

65. Trentham-Dietz A, Newcomb PA, Nichols HB, Hampton JM (2007) Breast cancer risk factors and second primary malignancies among women with breast cancer. Breast Cancer Res Treat 105:195-207

66. Miller MEMS, Olcese C, Patil S, Morrow M, Van Zee KJ (2017) Contralateral breast cancer risk in women with ductal carcinoma in situ: is it high enough to justify bilateral mastectomy? Ann Surg Oncol 24:2889-2897

67. Wärnberg FGH, Emdin S et al (2014) Effect of radiotherapy after breast-conserving surgery for ductal carcinoma in situ: 20 years follow-up in the randomized SweDCIS Trial. J Clin Oncol 32:3613-3618

68. Falk RSHS, Skaane P, Haldorsen T (2011) Second events following ductal carcinoma in situ of the breast: a register-based cohort study. Breast Cancer Res Treat 129:929-938

69. Graeser MK, Engel C, Rhiem K, Gadzicki D, Bick U, Kast K, Froster UG, Schlehe B, Bechtold A, Arnold N, Preisler-Adams S, Nestle-Kraemling C, Zaino M, Loeffler M, Kiechle M, Meindl A, Varga D, Schmutzler RK (2009) Contralateral breast cancer risk in BRCA1 and BRCA2 mutation carriers. J Clin Oncol 10:5887-5892

70. Schmidt MK, Hogervorst F, van Hien R et al (2016) Ageand tumor subtype-specific breast cancer risk estimates for CHEK2*1100delC carriers. J Clin Oncol 34:2750-2760 
71. van der Kolk DM, de Bock G, Leegte BK, Schaapveld M, Mourits MJ, de Vries J, van der Hout AH, Oosterwijk JC (2010) Penetrance of breast cancer, ovarian cancer and contralateral breast cancer in BRCA1 and BRCA2 families: high cancer incidence at older age. Breast Cancer Res Treat 124:643-651

72. Nichols HB, de González AB, Lacey JV Jr, Rosenberg PS, Anderson WF (2011) Declining incidence of contralateral breast cancer in the United States from 1975 to 2006. J Clin Oncol 20:1564-1569

73. van den Broek AJ, van't Veer L, Hooning MJ, Cornelissen S, Broeks A, Rutgers EJ, Smit VT, Cornelisse CJ, van Beek M, Janssen-Heijnen ML, Seynaeve C, Westenend PJ, Jobsen JJ, Siesling S, Tollenaar RA, van Leeuwen FE, Schmidt MK (2016) Impact of age at primary breast cancer on contralateral breast cancer risk in BRCA1/2 mutation carriers. J Clin Oncol 34:409-418

74. Hatcher MFL (2001) The psychosocial impact of bilateral prophylactic mastectomy: prospective study using questionnaires and semistructured interviews. BMJ 322:76

75. Nelson JATJ, Domchek S, Sonnad SS, Serletti JM, Wu LC (2012) Breast reconstruction in bilateral prophylactic mastectomy patients: factors that influence decision making. J Plast Reconstr Aesthet Surg 65:1481-1489

76. Cheng H, Chen B-H, Soleas IM, Ferko NC, Cameron CG, Hinoul $P$ (2017) Prolonged operative duration increases risk of surgical site infections: a systematic review. Surg Infect 18:722-735

77. Korol EJK, Waser N et al (2013) A systematic review of risk factors associated with surgical site infections among surgical patients. PLoS ONE 8:e83743

78. Wg C (2006) Risk factors for surgical site infection. Surg Infect 7:7-11

79. Lucci AML, Beitsch PD, Whitworth PW, Reintgen DS, Blumencranz PW, Leitch AM, Saha S, Hunt KK, Giuliano AE (2007) Surgical complications associated with sentinel lymph node dissection (SLND) plus axillary lymph node dissection compared with SLND alone in the American College of Surgeons Oncology Group Trial Z0011. J Clin Oncol 25:3657-3663

80. Behranwala KA, Dua R, Ross GM, Ward A, A'hern R, Gui GP (2006) The influence of radiotherapy on capsule formation and aesthetic outcome after immediate breast reconstruction using biodimensional anatomical expander implants. J Plast Reconstr Aesthet Surg 59:1043-1051

81. Spear SLOC (2000) Staged breast reconstruction with saline-filled implants in the irradiated breast: recent trends and therapeutic implications. Plast Reconstr Surg 105:930-942

82. Cordeiro PGPA, Disa JJ, McCormick B, VanZee K (2004) Irradiation after immediate tissue expander/implant breast reconstruction: outcomes, complications, aesthetic results, and satisfaction among 156 patients. Plast Reconstr Surg 113:877-881

83. Krueger EAWE, Strawderman M, Cederna P, Goldfarb S, Vicini FA, Pierce LJ (2001) Complications and patient satisfaction following expander/implant breast reconstruction with and without radiotherapy. Int J Radiat Oncol 49:713-721
84. Garvey EMGR, Wasif N, Casey WJ, Rebecca AM, Kreymerman P, Bash D, Pockaj BA (2014) Neoadjuvant therapy and breast cancer surgery a closer look at postoperative complications. Am J Surg 206:894-898

85. Colwell ASDB, Zahedi B, Medford-Davis L, Hertl C, Austen WG $\mathrm{Jr}$ (2011) Retrospective review of 331 consecutive immediate single-stage implant reconstructions with acellular dermal matrix: indications, complications, trends, and costs. Plast Reconstr Surg 128:1170-1178

86. Katz SJ, Hawley ST, Hamilton AS et al (2018) Surgeon influence on variation in receipt of contralateral prophylactic mastectomy for women with breast cancer. JAMA Surg 153:29-36

87. NCCN Clinical Practice Guidelines in Oncology: Breast Cancer Risk Reduction. National Comprehensive Cancer Network (NCCN), 2018

88. Chung AHK, Lawrence C, Sim MS, Giuliano A (2012) Comparison of patient characteristics and outcomes of contralateral prophylactic mastectomy and unilateral total mastectomy in breast cancer patients. Ann Surg Oncol 19:2600-2606

89. Yi M, Hunt K, Arun B, Bedrosian I, Gutierrez Barrera A, Do KA, Kuerer H, Babiera G, Mittendorf E, Ready K, Litton J, MericBernstam F (2015) Factors impacting the decision of breast cancer patients to undergo contralateral prophylactic mastectomy. Cancer Preserv Res 3:1026-1034

90. King TASR, Patil S, Gurevich I, Stempel M, Sampson M, Morrow M (2011) Clinical management factors contribute to the decision for contralateral prophylactic mastectomy. J Clin Oncol 29:2158-2164

91. Koslow SPL, Scott AM, Stempel M, Morrow M, Pusic AL, King TA (2013) Long-term patient-reported satisfaction after contralateral prophylactic mastectomy and implant reconstruction. Ann Surg Oncol 20:3422-3429

92. Rizzo AGE, Benacquista T, Draper L, Conejero AL, Weichman KE (2018) Abstract 71: postoperative quality of life in patients undergoing contralateral prophylactic mastectomy with breast reconstruction. Plast Reconstr Surg Glob Open 6:56-57

93. Jagsi R, Hawley ST, Griffith KA et al (2017) Contralateral prophylactic mastectomy decisions in a population-based sample of patients with early-stage breast cancer. JAMA Surg 152:274-282

94. Agarwal SKK, Kraft CT et al (2015) Defining the relationship between patient decisions to undergo breast reconstruction and contralateral prophylactic mastectomy. Plast Reconstr Surg 135:661-670

Publisher's Note Springer Nature remains neutral with regard to jurisdictional claims in published maps and institutional affiliations. 